\title{
Skeletal isomerisation of oleic acid over ferrierite: Influence of acid site number, accessibility and strength on activity and selectivity
}

\author{
Sophie C.C. Wiedemann ${ }^{\mathrm{a}, \mathrm{b}}$, Ara Muñoz-Murillo ${ }^{\mathrm{a}}$, Ramon Oord ${ }^{\mathrm{a}}$, Tanja van Bergen-Brenkman ${ }^{\mathrm{b}}$, Bas Wels $^{\mathrm{b}}$, \\ Pieter C.A. Bruijnincx ${ }^{a}$, Bert M. Weckhuysen ${ }^{a, *}$ \\ ${ }^{a}$ Inorganic Chemistry and Catalysis, Debye Institute for Nanomaterials Science, Utrecht University, Universiteitsweg 99, 3584 CG Utrecht, The Netherlands \\ ${ }^{\mathrm{b}}$ Croda Nederland, B.V., PO Box 2, 2800 AA Gouda, The Netherlands
}

\section{A R T I C L E I N F O}

\section{Article history:}

Received 6 December 2014

Revised 11 April 2015

Accepted 14 May 2015

Available online 9 June 2015

\section{Keywords:}

Ferrierite

Alkyl isomerisation

Branched-chain unsaturated fatty acids

Pore-mouth catalysis

\begin{abstract}
A B S T R A C T
Protonated ferrierite shows superior activity and selectivity in the liquid-phase isomerisation of linear unsaturated fatty acids to (mono-)branched-chain unsaturated fatty acids, (Mo)BUFA. This high selectivity is remarkable, as most of the interior surface of the zeolite is blocked already at the onset of reaction, limiting reaction to the pore mouth. A detailed study of the relationship between ferrierite acidity and performance is reported for five commercial catalysts; significant differences were found, independently of their bulk Si/Al ratios. Initial pore conversion correlates with Brønsted acidity in the 10-MR channels, as determined by adsorption/desorption of pyridine and FTIR. A low density of external acid sites reduces oligomerisation of fatty acids, while a high ratio of Brønsted to Lewis sites explains the observed high BUFA yield. The combination of FTIR with $\mathrm{CO}$ adsorption, and temperature-programmed desorption of $\mathrm{NH}_{3}$, confirms that the presence of strong but few Brønsted acid sites in the 10-MR channels increases selectivity to MoBUFA.
\end{abstract}

(c) 2015 Elsevier Inc. All rights reserved.

\section{Introduction}

In the gas-phase isomerisation of butene to isobutene, the major challenge in achieving a high selectivity to isobutene is addressing the competition with butene oligomerisation, as both reactions share the same carbocation transition state. The remarkable selectivity and stability of the medium-pore zeolite ferrierite for this reaction, has been extensively studied [1-3]. Although the exact mechanism of isomerisation is still a matter of discussion, the excellent performance of this zeolite is commonly agreed to be a direct consequence of its unique topology. Ferrierite's 10 -membered (MR) channels $(4.2 \times 5.4 \AA)$ are perpendicularly crossed with the 8-MR channels $(3.4 \times 4.7 \AA)$ [4], with the latter also containing spherical cavities of 6-7 $\AA$ with 6- and 5-MR windows. In addition to pore size, the void volume available at the channel intersections must also play a role. When compared to MFS and STI (two other two-dimensional 10- and 8-MR channel zeolites with similar micropore volumes), 3-methylpentane adsorption capacity and rate measurements have shown that ferrierite is characterised by the most restrictive micropore structure [5]; this constrains the transition state, enhancing selectivity to

\footnotetext{
* Corresponding author.

E-mail address: B.M.Weckhuysen@uu.nl (B.M. Weckhuysen).
}

isomerisation above oligomerisation [6]. At longer time-on-stream (TOS), the selectivity to isobutene was found to increase significantly; this was believed to be due to blocking of the channels, leaving only the acid sites near the 10-MR pore mouth available for the isomerisation reaction [7,8]. Parameters such as the specific ellipticity of the pore mouth, and the crystallite size (which is inversely proportional to the number of pore mouths), have been found to correlate with selectivity [8], supporting the above hypothesis. However, despite such evidence, pore-mouth catalysis has remained a subject of debate for butene isomerisation.

In addition to the specific location of acid sites as a function of pore topology and morphology, the precise nature of the acidic sites in ferrierite also plays an important role in selective skeletal isomerisation. High isobutene yields thus require Brønsted acid sites with intermediate acidity [9], while the simultaneous presence of Lewis sites and/or highly acidic Brønsted sites instead promotes oligomerisation and cracking reactions [10]. Notably, the protonated form of Ferrierite (H-Fer) is characterised by a low ratio of Lewis to Brønsted acid sites compared to other 10-MR zeolites (Table 1 in [11]). Other important parameters are the location and distribution of the active sites inside, and on the surface of, the catalyst crystallite. Five different Brønsted acidic sites could be distinguished in H-Fer, based on their FTIR fingerprint; hydroxyl 
Table 1

Literature data reported for the acidity of commercial ferrierites after protonation.

\begin{tabular}{|c|c|c|c|c|c|c|c|}
\hline $\begin{array}{l}\text { Sample \# in this } \\
\text { study }\end{array}$ & $\begin{array}{l}\text { Commercial } \\
\text { name }\end{array}$ & $\begin{array}{l}\mathrm{Si} / \mathrm{Al} \\
\text { ratio }^{\mathrm{a}}\end{array}$ & $\begin{array}{l}\text { Brønsted acidity by MAS NMR } \\
(\mathrm{mmol} / \mathrm{g})[17]\end{array}$ & $\begin{array}{l}\text { Brønsted acidity by FTIR } \\
(\mathrm{mmol} / \mathrm{g})[17]\end{array}$ & $\begin{array}{l}\text { Acid strength } \Delta v \mathrm{CO} \\
\left(\mathrm{cm}^{-1}\right)[17]\end{array}$ & $\begin{array}{l}\mathrm{CEC}^{\mathrm{b}}(\mathrm{mmol} / \\
\mathrm{g})[16]\end{array}$ & $\begin{array}{l}\text { EFAl }(\mathrm{mmol} / \\
\text { g) [16] }\end{array}$ \\
\hline 2 & HSZ720KOA & 8.9 & 1.389 & 1.172 & 286 & ND & ND \\
\hline 4 & СР914C & 10.0 & 0.904 & 0.840 & 295 & 0.92 & 0.64 \\
\hline 5 & CP914 & 27.5 & ND & ND & ND & 0.40 & 0.15 \\
\hline
\end{tabular}

a Determined by chemical wet analysis.

b $\mathrm{CEC}=$ Cation-exchange Capacity from $\mathrm{NH}_{3}$ during calcination.

groups in 10-MR channels $(20 \%$ of $\mathrm{Si}(\mathrm{OH}) \mathrm{Al})$, in large pockets of the 8-MR channels ( $50 \%$ of $\mathrm{Si}(\mathrm{OH}) \mathrm{Al}$ ), in the 8-MR channels and finally in the 6-MR and 5-MR-windowed cavities [12]. Their distribution has since been found to vary with the template (when the synthesis is performed in the absence of sodium cations) and can therefore be controlled by optimising the synthetic procedure [13]. FTIR studies using bulky probe molecules furthermore showed that the external surface of protonated ferrierite has terminal silanols (some with significant Brønsted acidity), as well as Lewis acid sites, but no bridging hydroxyl groups [14]. However, such information on the location and density of acid sites in ferrierites does not yet allow one to correlate structure with catalytic activity, since accessibility of the Brønsted acidic sites in relation to the size, shape and polarity of the reactant molecules also plays a key role.

The key role that acidity plays in isomerisation reactions is illustrated by the literature, where the relation between acidity and performance has been studied for some commercial ferrierite grades. A number of parameters describing the acidity of these samples are listed in Table 1. These ferrierites show different selectivities in the gas-phase transformation of butene to isobutene; selectivity to isobutene has been reported to increase with $\mathrm{Si} / \mathrm{Al}$ ratio [15] and with an optimum amount of extra-framework aluminium (EFAl) [16]. However, the selectivity of ferrierite samples with very similar $\mathrm{Si} / \mathrm{Al}$ ratio has been found to differ significantly in the liquid-phase isomerisation of monoterpene hydrocarbons [17]. A combination of techniques (MAS NMR and FTIR) confirmed that the $\mathrm{Si} / \mathrm{Al}$ ratio alone is indeed not sufficient to predict the catalytic performance, and acidity needs to be described in more specific terms, that is, the precise type, strength, location and accessibility of the sites.

Recently, H-Fer has also been found to show superior activity and selectivity in the liquid-phase isomerisation of linear unsaturated fatty acids to branched-chain species (Branched-chain Unsaturated Fatty Acids or BUFA, Scheme 1) [18]. Quantitative oleic acid (OA) conversion and BUFA yields above $70 \% \mathrm{~m} / \mathrm{m}$ have been reported, representing a step change compared to the numerous zeolite types previously investigated. As in butene isomerisation, the unique topology of ferrierite is believed to be responsible for the transition-state selectivity observed. Further improvements in BUFA production were made by the use of the bulky Lewis base triphenylphosphine (TPP), which has been shown to enhance selectivity by binding to the external acid sites and suppressing residual oligomerisation at the zeolite surface [19]. The selectivity that ferrierite displays in this reaction is remarkable, given the fact that the zeolite shows severe deactivation already after very short reaction times. The deactivation has been shown to proceed via two mechanisms: Firstly, pore blockage occurs from a very early stage in the reaction, with dodecylbenzene and its precursors having been identified as the major coke constituents. Secondly, activity is further reduced due to acid site poisoning, caused by strong adsorption of polyenylic species formed by hydrogen transfer reactions [20]. These modes of deactivation imply that from the very early stages of reaction, only the pore mouth is participating in catalysis.

In addition to its selectivity to isomerisation over oligomerisation, the ferrierite topology promotes a very specific branching pattern. The BUFA obtained by H-Fer-catalysed alkyl isomerisation are a mixture of at least 30 alkyl isomers, predominantly methyl-branched ones [19]. Mono-branched fatty acids (MoBUFA) dominate the reaction mixture with the methyl group being found preferentially at positions 8-14 [19]. Ethyl-branching and propyl-branching are not reported, which is in contrast to fatty acid isomerisation reactions performed with larger pore zeolites [21]. Multiple-branched fatty acid isomers are detected, albeit in limited amounts in ferrierite-catalysed reactions, and are believed to be formed by successive rearrangements [21]; this multiple branching occurs preferentially at specific positions along the carbon chain, that is, 11,14 and 14, 15 [19], excluding any quaternary carbon formation [19,21]. The MoBUFA are of particular commercial interest; single methyl-branched fatty acids have been shown to maintain good biodegradability [22], and the position of the methyl group close to the centre of the molecule ensures maximum impact on low-temperature properties [23], highly desirable in, for example, lubricant applications [24]. Furthermore, oleochemicals derived from hydrogenated BUFA are reported to bring performance benefits in many consumer and industrial applications [21,25-27], and the special properties of the MoBUFA are similarly expected to be carried over in their derivatives. Therefore, it is important to optimise MoBUFA yield and to understand how to control and limit the formation of multiple-branched products.

In this paper, we present our findings regarding the liquid-phase skeletal isomerisation of $\mathrm{OA}$ in the presence of various ferrierite catalysts. Five samples, four of which have very similar $\mathrm{Si} / \mathrm{Al}$ ratios, were obtained from two manufacturers - in order to explore how subtle differences in morphology and acidity, including type, strength, location and accessibility of the acid sites, influence the results of catalytic testing. A number of complementary characterisation techniques have been combined to measure these key parameters, building on prior studies of established gas and

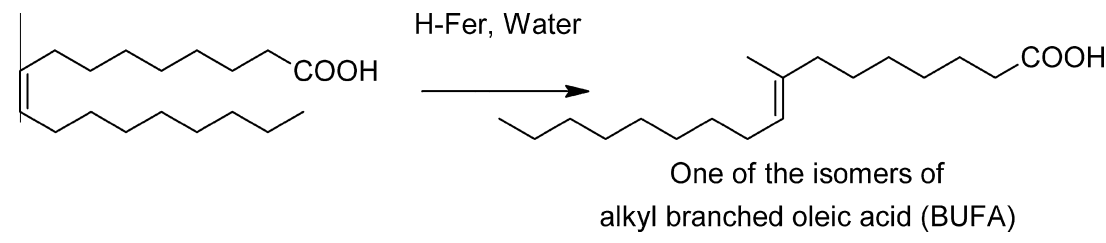

Scheme 1. Skeletal isomerisation of OA in the presence of H-Fer. 
liquid-phase reactions involving ferrierite. We focused on understanding the origin of the superior activity and selectivity towards (Mo)BUFA in the alkyl isomerisation of oleic acid.

\section{Experimental}

\subsection{Chemicals and catalyst material}

Distilled OA with trade name Priolene ${ }^{\mathrm{TM}} 6936$ (92.2\% C18:1, $3.2 \% \mathrm{C} 18: 2,0.2 \mathrm{C} 18: 3$ and $3.7 \%$ saturated fatty acids, mainly octadecanoic) was obtained from Croda.

The ferrierite samples used are listed in Table 2. Sample 2, received in the sodium/potassium cation form, was activated by conversion to its protonated form, henceforth denoted as H-Fer, using an ion-exchange procedure with hydrochloric acid $(\mathrm{HCl}$, $1 \mathrm{M}$ ) at room temperature (RT) [28], before air drying for three days at RT. All samples received in the ammonia form were calcined for $5 \mathrm{~h}$ at $500{ }^{\circ} \mathrm{C}$. For completeness, the XRD patterns of all catalysts were recorded after activation (data not shown); they were found to be consistent with the ferrierite structure and free of crystalline impurities. Based on the intensity of a number of characteristic diffraction lines, catalyst 1 shows somewhat lower crystallinity.

$\mathrm{PtO}_{2}$ was purchased from Sigma Aldrich (Pt 80-85\% and surface area $\geqslant 75 \mathrm{~m}^{2} / \mathrm{g}$ ).

\subsection{Catalytic testing}

All catalytic testing was carried out with $1.5 \% \mathrm{~m} / \mathrm{m}$ loading at two different scales as follows:

- A 1.8 L RC1 high-pressure reactor from Mettler Toledo was used to study both activity and selectivity starting with the following amounts: $1000 \mathrm{~g} \mathrm{OA}, 15.0 \mathrm{~g} \mathrm{H}-\mathrm{Fer}$ and $10.0 \mathrm{~g}$ demineralised water. After purging with nitrogen 3 times, the reactor was stirred with a mechanical stirrer at $400 \mathrm{rpm}$, pressurised to about $1 \mathrm{bar}$ and heated to (a maximum of) $260^{\circ} \mathrm{C}$ at a rate of $6{ }^{\circ} \mathrm{C} / \mathrm{min}$, resulting in a pressure of about 11 bar. Reaction temperature was typically held for $6 \mathrm{~h}$ (unless otherwise stated), before the mixture was cooled to $80{ }^{\circ} \mathrm{C}$ and filtered under nitrogen for a minimum of $4 \mathrm{~h}$.

- A $15 \mathrm{~mL}$ multi-autoclave SPR16generation2 from Amtech was used to compare the initial activities starting with the following amounts: $7.0 \mathrm{~g} \mathrm{OA}, 105.0 \mathrm{mg} \mathrm{H}-\mathrm{Fer}$ and $73.0 \mu \mathrm{l}$ demineralised water. Reactors were stirred with a magnetic stirrer at $500 \mathrm{rpm}$ and purged with nitrogen 3 times, before heating them to (a maximum of) $260{ }^{\circ} \mathrm{C}$; pressures between 6 and 7 bar were recorded. After a few minutes at reaction temperature (to achieve conversions of $10-20 \%$ ), the reactors were cooled to $50{ }^{\circ} \mathrm{C}$ and their content was directly filtered using a syringe filter (PTFE, $0.45 \mu \mathrm{m}$ ).

Because of the large differences in molecular weight of the components in the crude reaction mixture, its composition was

Table 2

Overview of ferrierite samples tested.

\begin{tabular}{|c|c|c|c|c|c|}
\hline $\begin{array}{l}\text { Catalyst } \\
\#\end{array}$ & Name & Supplier & $\begin{array}{l}\text { Supplied } \\
\text { form }\end{array}$ & $\begin{array}{l}\text { Nominal }^{\mathrm{a}} \\
\mathrm{Si} / \mathrm{Al}\end{array}$ & $\begin{array}{l}\text { Activation } \\
\text { method }\end{array}$ \\
\hline 1 & CP7145 & Zeolyst & $\mathrm{NH}_{4}^{+}$ & 8.5 & Calcination \\
\hline 2 & HSZ720KOA & Tosoh & $\mathrm{K}^{+}$ & 8.5 & $\begin{array}{l}\text { Wet } \\
\text { exchange }\end{array}$ \\
\hline 3 & HSZ722HOA & Tosoh & $\mathrm{H}^{+}$ & 10 & 1 \\
\hline 4 & СР914C & Zeolyst & $\mathrm{NH}_{4}^{+}$ & 10 & Calcination \\
\hline 5 & СР914 & Zeolyst & $\mathrm{NH}_{4}^{+}$ & 27.5 & Calcination \\
\hline
\end{tabular}

a Commercial values. determined in two steps. First, the oligomer concentration in the crude reaction mixture was determined by high-temperature GC (HT-GC). Secondly, the monomeric fraction was separated from the oligomers by distillation at a temperature of $260{ }^{\circ} \mathrm{C}$ under a pressure of $<1$ mbar. Subsequently, to reduce chemical complexity and facilitate analyses, a small amount of the collected monomeric fraction was diluted in ethyl acetate $(40 \mathrm{mg} / \mathrm{mL})$, hydrogenated at RT for $45 \mathrm{~min}$ using $40 \mathrm{mg}$ Adam's catalyst $\left(\mathrm{PtO}_{2}\right.$ reduced in situ, hydrogen flow of $50 \mathrm{~mL} / \mathrm{min}$ ) and subjected to GC analyses.

OA (with an initial mass fraction $\left.x_{\mathrm{C} 18: 1,0}\right)$, linoleic acid $\left(x_{\mathrm{C} 18: 2,0}\right)$ and linolenic acid $\left(x_{\mathrm{C} 18: 3,0}\right)$ are considered as the reactive components of OA. Their mass conversion $\left(y_{\mathrm{t}}\right)$ was determined by quantification of the mass fraction of stearic acid $\left(x_{\mathrm{C} 18, \mathrm{t}}\right)$ in the hydrogenated monomer fraction as a function of time $t$. The onset of the reaction $(t=0)$ is designated as the time when the reaction mixture reaches the temperature set point of $260^{\circ} \mathrm{C}$. A correction is made for the distillation yield of the monomeric species $\left(y_{\mathrm{M}, \mathrm{t}}\right)$ as determined by HT-GC, and for the initial mass fraction of unreactive species, that is, the amount of stearic acid $\left(x_{\mathrm{C} 18,0}\right)$ present in $\mathrm{OA}$. The mass conversion of all unsaturated components, subsequently referred to simply as "conversion", is then given by

$y_{\mathrm{t}}=1-\frac{\left[\left(x_{\mathrm{C} 18, \mathrm{t}}+x_{\mathrm{C} 18: 1, \mathrm{t}}\right) \times y_{\mathrm{M}, \mathrm{t}}-x_{\mathrm{C} 18,0}\right]}{\left[x_{\mathrm{C} 18: 1,0}+x_{\mathrm{C} 18: 2,0}+x_{\mathrm{C} 18: 3,0}\right]}$

Note that due to the similar molecular weights of these molecules, mole and mass conversions can be considered almost equivalent; positional and cis/trans isomers are implicitly included in the simplified nomenclature.

The selectivity towards BUFA $\left(s_{B, t}\right)$ is derived from the mass fraction of all hydrogenated BUFA $\left(x_{\mathrm{B}, \mathrm{t}}\right)$ in the hydrogenated monomer fraction. Again, a correction is made for the distillation yield of the monomeric species $\left(y_{\mathrm{M}, \mathrm{t}}\right)$ :

$s_{\mathrm{B}, \mathrm{t}}=\frac{\left[x_{\mathrm{B}, \mathrm{t}} \times y_{\mathrm{M}, \mathrm{t}}\right]}{\left[\left(x_{\mathrm{C} 18: 1,0}+x_{\mathrm{C} 18: 2,0}+x_{\mathrm{C} 18: 3,0}\right) \times y_{\mathrm{t}}\right]}$

The selectivity towards MoBUFA is calculated in a similar way from the mass fraction of all hydrogenated MoBUFA $\left(x_{\mathrm{MoB}, \mathrm{t}}\right)$ in the hydrogenated monomer fraction.

\subsection{Catalyst characterisation}

The SEM images were recorded using a FEI XL30SFEG microscope.

The particle size distributions for the crystal agglomerates were compared by static light scattering (Malvern Mastersizer 2000). All samples were analysed in duplicate as $7.5 \mathrm{mg} / \mathrm{mL}$ dispersions in water under sonication.

Nitrogen physisorption on the catalyst materials was performed with an automated gas sorption system, Micromeritics TriStar 3000. Before the measurements, the samples were outgassed for $12 \mathrm{~h}$ at $250^{\circ} \mathrm{C}$. The external surface area $\left(S_{\mathrm{E}}\right)$, micropore surface area $\left(S_{\mu}\right)$ and micropore volume $\left(V_{\mu}\right)$ were determined by applying the $\mathrm{t}$-plot method. The relative standard deviations for these parameters have been calculated for sample 2 (as a typical example) after repeating the analyses 4 times and were $7 \%, 24 \%$ and $3 \%$ respectively.

For Pyridine (Py) adsorption, IR spectra of the catalyst materials were obtained by first pressing the material into a self-supporting wafer of $12-16 \mathrm{mg}$ with a $13 \mathrm{~mm}$ diameter. The wafer was placed in a dedicated FTIR cell connected to an oven. Adsorbed water was removed by heating the sample to $550{ }^{\circ} \mathrm{C}$ at $4{ }^{\circ} \mathrm{C} / \mathrm{min}$ under vacuum $\left(10^{-2}\right.$ mbar). A Perkin-Elmer System 2000 was used to record the FTIR spectra in transmission mode from 4000 to $400 \mathrm{~cm}^{-1}$ (resolution of $4 \mathrm{~cm}^{-1}$ and 12 scans), with the spectrum of the empty cell as background (ratio). Py was adsorbed in situ at $50{ }^{\circ} \mathrm{C}$ on 
the dried wafer. The temperature of the cell was increased to $150{ }^{\circ} \mathrm{C}$ and kept at this temperature for 30 min to remove any physisorbed molecules, before recording the FTIR spectra. All the spectra have been normalised to the overtone range $1750-2100 \mathrm{~cm}^{-1}$.

For CO adsorption, self-supporting wafers of $13-18 \mathrm{mg}$ with a $13 \mathrm{~mm}$ diameter were prepared. The wafer was placed in a well-sealed FTIR cell connected to an oven. Adsorbed water was removed by heating the sample to $400{ }^{\circ} \mathrm{C}$ at $4{ }^{\circ} \mathrm{C} / \mathrm{min}$ under vacuum $\left(10^{-6} \mathrm{mbar}\right)$ and holding this temperature for one hour before cooling. The same Perkin-Elmer System 2000 was used to record the FTIR spectra in transmission mode from 4000 to $1000 \mathrm{~cm}^{-1}$ (resolution of $4 \mathrm{~cm}^{-1}$ and 25 scans), with the spectrum of the empty cell as background (ratio). CO (10\% in He, purity 99.9\%) was adsorbed in situ at low temperature $\left(-188^{\circ} \mathrm{C}\right)$ on the dried wafers. Spectra were taken at several pressures (from 5 to $10^{-4}$ mbar), while adsorbing and desorbing CO. The spectra of the dried wafers recorded before adsorption at $-188^{\circ} \mathrm{C}$ were deconvoluted in the range $3730-3200 \mathrm{~cm}^{-1}$ using the Matlab-based BluePrintXAS software. The IR band areas were normalised by the wafer density.

The XPS measurements were carried out with a Thermo Scientific K-Alpha, equipped with a monochromatic small-spot $\mathrm{X}$-ray source and a $180^{\circ}$ double focusing hemispherical analyser with a 128-channel detector. Spectra were obtained using an aluminium anode ( $\mathrm{Al} \mathrm{K \alpha}=1486.6 \mathrm{eV}$ ) operating at $72 \mathrm{~W}$ and a spot size of $400 \mu \mathrm{m}$. Survey scans were measured at a constant pass energy of $200 \mathrm{eV}$ and region scans at $50 \mathrm{eV}$. The background pressure was $2 \times 10^{-9}$ mbar and during measurement $3 \times 10^{-7} \mathrm{mbar}$ argon because of the dual-beam charge compensation. Sputtering (for $30 \mathrm{~s}$ and $300 \mathrm{~s}$ ) was done with an energy beam of $1000 \mathrm{eV}$ at low current, for monitoring of the $\mathrm{Si} / \mathrm{Al}$ ratio in depth. C $1 \mathrm{~s}, \mathrm{O} 1 \mathrm{~s}$, Si 2p and Al 2p bands were recorded.

A Varian Cary 500 Scan spectrophotometer was used to record the UV-Vis spectra of the catalyst materials in diffuse reflectance mode, in the range $200-800 \mathrm{~nm}$ (scan speed $600 \mathrm{~nm} / \mathrm{min}$ and 1 cycle). Prior to analysis, $1.0 \mathrm{~g}$ H-Fer catalyst in $60 \mathrm{ml}$ acetone was stirred with 5\% TPP on H-Fer for $24 \mathrm{~h}$ at RT. The excess of TPP was removed by washing the sample with acetone four times (i.e., until TPP could not be detected in the filtrate).

TPD was carried out using a Micromeritics Autochem II, equipped with a thermal conductivity detector (TCD). Prior to analyses, $0.100-0.110 \mathrm{mg}$ of sample was dried by heating in a stream of $\mathrm{He}\left(50 \mathrm{~cm}^{3} / \mathrm{min}\right)$ at a heating rate of $10^{\circ} \mathrm{C} / \mathrm{min}$ to $600^{\circ} \mathrm{C}$ and subsequently cooled to $100^{\circ} \mathrm{C}$. Ammonia was added via pulses, and kept in a $25 \mathrm{~cm}^{3} / \mathrm{min}$ He flow for $60 \mathrm{~min}$, before increasing the temperature at $5{ }^{\circ} \mathrm{C} / \mathrm{min}$ to $600{ }^{\circ} \mathrm{C}$.

\section{Results}

This study is based on a series of five commercial ferrierites showing significant differences in activity and selectivity, of which four have very similar nominal Si/Al ratio (Table 2 ). The specified $\mathrm{Si} / \mathrm{Al}$ ratio for samples 1 and 2 is 8.5 , while the nominal bulk acidity of catalysts 3 and 4 is somewhat lower $(\mathrm{Si} / \mathrm{Al}$ ratio $=10)$. Sample 5 , with a much lower acidity ( $\mathrm{Si} / \mathrm{Al}$ ratio $=27.5$ ), has been included for comparison. All catalysts are used in their protonated form, obtained by calcination of the ammonium form (1,4 and 5) or after $\mathrm{HCl}$ wet exchange (2). Sample 3 was received in its protonated form. The Si/Al ratios of all catalysts were determined prior to activation.

\subsection{Catalytic testing}

Protonated ferrierite undergoes a rapid and severe deactivation during the alkyl isomerisation reaction with OA as feedstock, resulting from two different mechanisms [20]. The rapid loss of internal surface area is due to pore blockage, which occurs even before the reaction temperature is reached. Catalysis is therefore confined to the pore mouth from the start, and any study of the initial activity must probe this pore-mouth region. Acid site deactivation, the second cause of deactivation, is not playing a major role at this early stage, and we can thus obtain a true picture of the catalyst potential by studying the initial activity.

Fig. 1 shows large differences between the catalysts in OA conversion (i.e., to all products) for the first $30 \mathrm{~min}$ of the reaction at $260{ }^{\circ} \mathrm{C}$ with a $1.5 \%$ loading. Within the first 5-10 min at reaction temperature, the conversion-time plots are approximately linear, indicating that the catalysts still retain most of their initial pore-mouth activity.

Catalyst 5 is characterised by the lowest activity, as was to be expected from its bulk acidity. On the other hand, the differences seen in activity for the other four samples are surprising, given their very similar $\mathrm{Si} / \mathrm{Al}$ ratios; their activity can be ranked in the following order: $2>3 \sim 1 \gg 4 \gg 5$. There is no correlation with the manufacture-specified $\mathrm{Si} / \mathrm{Al}$ ratio, as both 3 and 4 are characterised by a $\mathrm{Si} / \mathrm{Al}$ ratio of 10 . Therefore, this bulk parameter is insufficient to account for the observed differences in rate and, as for the isomerisation of monoterpene hydrocarbons, more discriminating measurements of texture and acidity are required to properly explain and predict their activity as catalysts.

It can be seen in Fig. 1 that the conversion-time plots do not pass through the origin, when $t=0$ is defined as the moment when the isomerisation reaction temperature is reached. The reason for this is that $\mathrm{OA}$ oligomerisation commences at somewhat lower temperatures than $\mathrm{OA}$ isomerisation. Indeed, it is known that estolides can be synthesised in high yield at $150^{\circ} \mathrm{C}$ using a $\mathrm{K}-10$ montmorillonite clay [29], and these estolides are also seen for most of the ferrierites tested here during the initial heating period. It is then assumed in comparing initial activity of the catalysts this way that the reactions taking place during the heating period are similar, which is largely confirmed by analysis of the reaction products. The differences in low-temperature activity that are indicated by the different intercept values must be related to the number

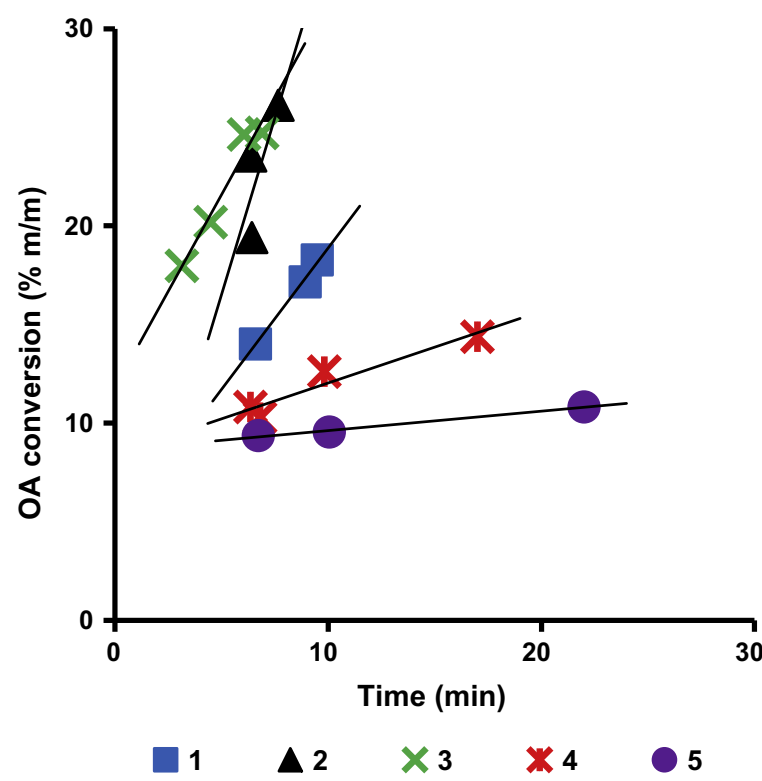

Fig. 1. Initial activity of the ferrierite catalysts, expressed as OA conversion, during the alkyl isomerisation of $\mathrm{OA}$ at $260{ }^{\circ} \mathrm{C}$ in the presence of $1.5 \%$ commercial H-Fer catalysts: 1 and $2(\mathrm{Si} / \mathrm{Al}=8.5) ; 3$ and $4(\mathrm{Si} / \mathrm{Al}=10) ; 5(\mathrm{Si} / \mathrm{Al}=27)$. 
and strength of unconstrained (and thus non-selective) acid sites on the external surface of the catalyst.

The conversions achieved with the H-Fer samples after more typical, elongated reaction times are illustrated by Fig. 2 . Catalysts 4 and 5 show the lowest conversion, as predicted from their low initial reaction rates. However, the ranking of the other catalysts changes to $3>1 \sim 2 \gg 4 \gg 5$, indicating that 1 and 3 are somewhat more stable to deactivation than 2 .

Additionally, the ferrierites show large differences in their selectivity. In order to allow a proper comparison, reaction times were selected such that $86-89 \%$ conversion was attained for each catalyst; beyond this conversion, oligomer yield increases significantly (Fig. 3a). Catalyst 5 was not able to reach this conversion level, though, and the reaction was stopped arbitrarily after $16 \mathrm{~h}$ (i.e., at $69 \% \mathrm{~m} / \mathrm{m}$ conversion). Fig. 3 b shows that each catalyst is characterised by a specific relation between BUFA and MoBUFA selectivity; for example, catalyst 4 produces almost exclusively MoBUFA while 2 more strongly promotes multiple branching.

Fig. 4 compares the selectivity at two levels of conversion. At $88 \%$ conversion ( $4 \mathrm{~b}$ ), the catalysts can be ranked: $4>3 \sim 1>2$. At lower conversion $(69 \%, 4 a)$, the selectivity of catalyst 5 is almost as good as 4; the differences between the others are somewhat smaller. Again, the acidity as determined by the Si/Al ratio cannot be linearly related to BUFA nor MoBUFA selectivity, although the experimental evidence points to an optimum which we estimate to be in the range of a $\mathrm{Si} / \mathrm{Al}$ ratio of $10-15$.

\subsection{Catalyst characterisation}

In order to explain the catalytic testing results and relate catalyst performance to structure, all catalysts were characterised in detail using a number of complementary techniques.

\subsubsection{Morphology}

Fig. 5 shows the scanning electron microscopy images (SEM) of the commercial H-Fer samples. All catalysts consist of plate-like crystals in the sub-micron range, with thicknesses ranging from 0.01 to $0.15 \mu \mathrm{m}$. While similar at first sight, the SEM images do show a number of important differences. The crystals of sample 4 , for instance, differ from the other samples, with very irregular shapes and rounded edges. The same catalyst is studied in [17],

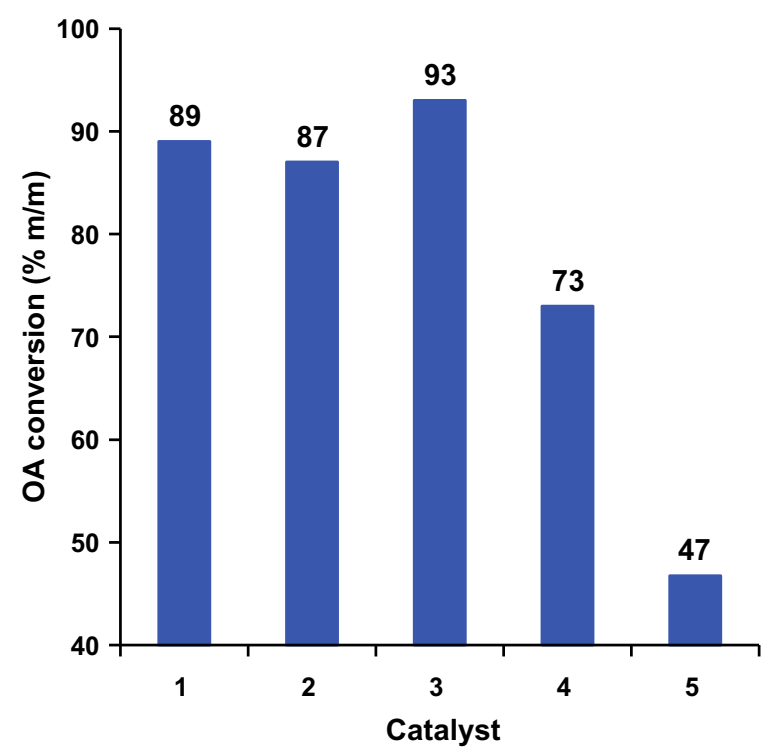

Fig. 2. OA conversion after $6 \mathrm{~h}$ of isomerisation at $260{ }^{\circ} \mathrm{C}$ in the presence of $1.5 \%$ commercial $\mathrm{H}$-Fer catalysts: 1 and $2(\mathrm{Si} / \mathrm{Al}=8.5) ; 3$ and $4(\mathrm{Si} / \mathrm{Al}=10) ; 5(\mathrm{Si} / \mathrm{Al}=27)$.

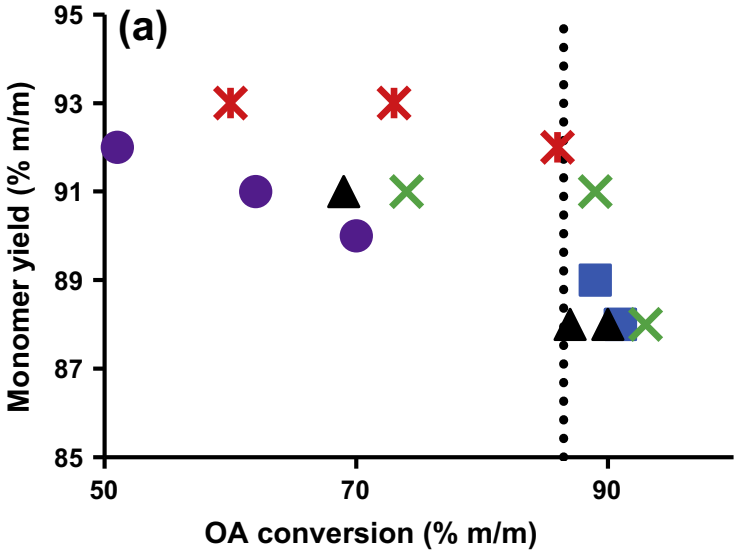

$1 \triangle 2 \times 3 \times 4 \bigcirc 5$

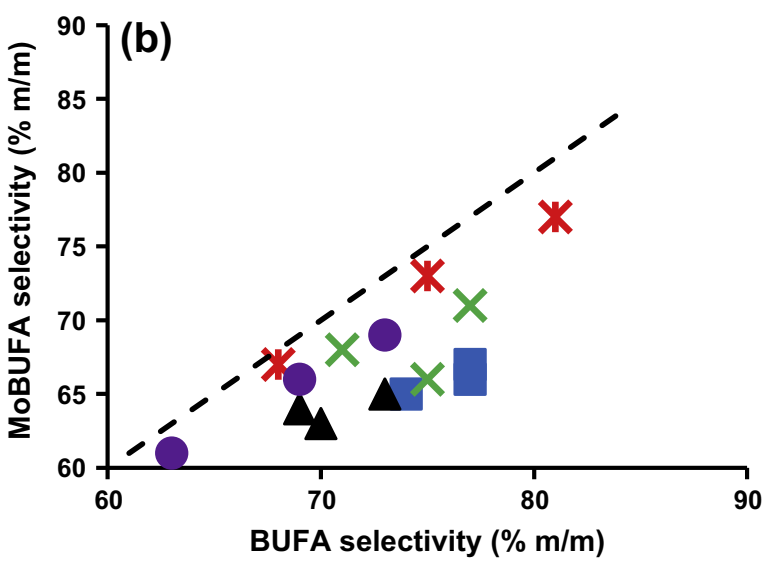

$1 \triangle 2 \times 3 \times 4 \bigcirc 5$

Fig. 3. $\mathrm{OA}$ isomerisation at $260{ }^{\circ} \mathrm{C}$ in the presence of a series of $1.5 \%$ commercial $\mathrm{H}$ Fer catalysts: 1 and $2(\mathrm{Si} / \mathrm{Al}=8.5) ; 3$ and $4(\mathrm{Si} / \mathrm{Al}=10) ; 5(\mathrm{Si} / \mathrm{Al}=27)$; a. Relation between monomer yield and OA conversion $(\% \mathrm{~m} / \mathrm{m})$; note that the monomer yields in 3a include unreacted OA; see exp. section for the definition of yield; b. Relation between MoBUFA and BUFA selectivity $(\% \mathrm{~m} / \mathrm{m})$ at different OA conversions.

where the authors suggested that a post-treatment, such as weak dealumination, had been applied; this explanation would be consistent with the observed morphology. The crystals of sample 5 , in turn, are somewhat larger $(0.5-2 \mu \mathrm{m})$. So in addition to the higher Si/Al ratio and resulting lower acidity, the low surface area per unit mass, and consequently fewer pore mouths, might thus also contribute to the very low conversion observed with this catalyst.

Static light scattering was used to determine the particle sizes of catalysts $1-4$, particle being defined here as crystal agglomerates. The results are summarised in Table 3 . Catalyst 2 consists of larger particles, with a diameter ranging from 3 to $36 \mu \mathrm{m}$ and a median at $15 \mu \mathrm{m}$. Catalysts 1,3 and 4 show very similar distributions, with a median diameter of 3 to $5 \mu \mathrm{m}$, but different activity. These differences in particle size thus cannot explain the catalytic data.

\subsubsection{Textural properties}

Surface area and porosity of the H-Fer series were determined by nitrogen physisorption measurements (Table 4). The external surface areas show a large variation, with the $S_{\mathrm{E}}$ of catalyst 1 $\left(52 \mathrm{~m}^{2} / \mathrm{g}\right.$ ) being $\sim 50 \%$ larger than for 2 or 5 (both $32 \mathrm{~m}^{2} / \mathrm{g}$ ). As $\mathrm{OA}$ isomerisation is thought to occur mostly via pore-mouth catalysis [20], this parameter should be taken into account when 
(a) $69 \% \mathrm{~m} / \mathrm{m}$ conversion

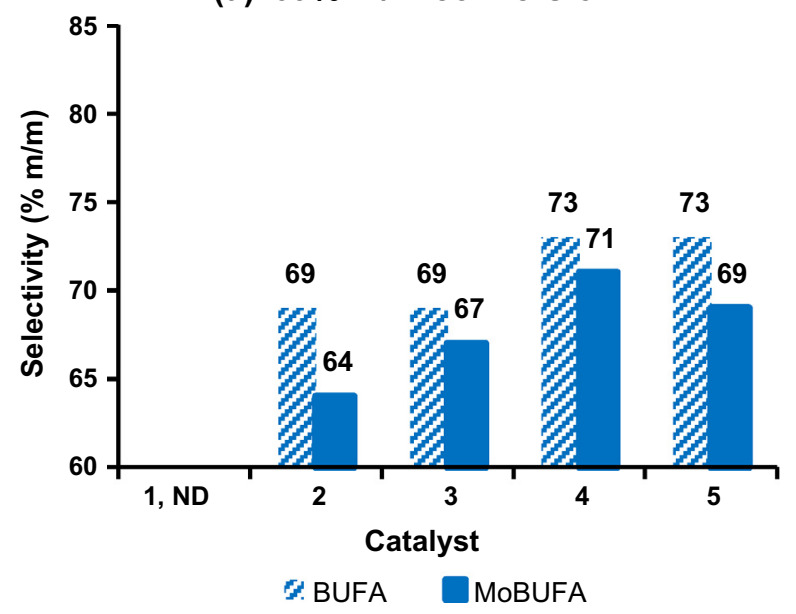

(b) $88 \% \mathrm{~m} / \mathrm{m}$ conversion

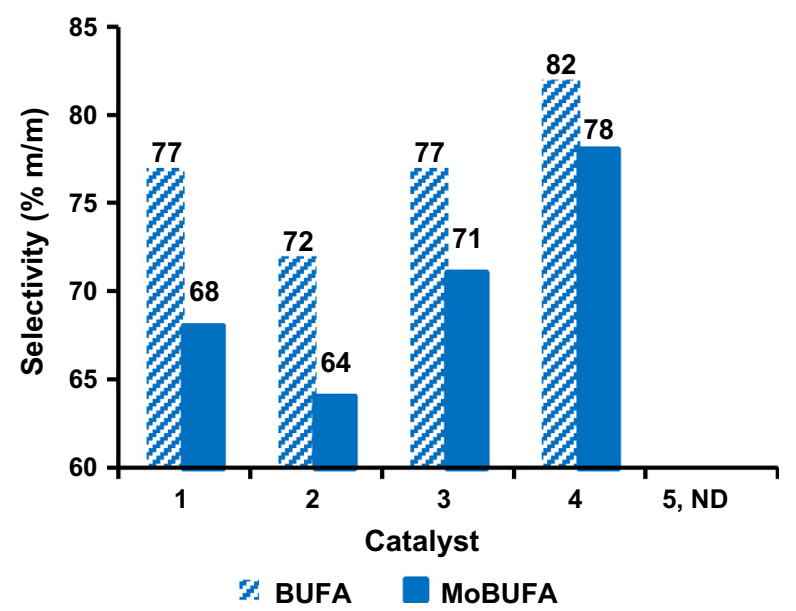

Fig. 4. $\mathrm{OA}$ isomerisation at $260^{\circ} \mathrm{C}$ in the presence of $1.5 \%$ commercial $\mathrm{H}$-Fer catalysts: 1 and $2(\mathrm{Si} / \mathrm{Al}=8.5) ; 3$ and $4(\mathrm{Si} / \mathrm{Al}=10) ; 5(\mathrm{Si} / \mathrm{Al}=27)$; Selectivities $(\% \mathrm{~m} /$ $\mathrm{m}$ ) to BUFA (diagonal fill) and MoBUFA (solid fill) at a. $69 \% \mathrm{~m} / \mathrm{m}$ conversion (1 not included) and b. $88 \% \mathrm{~m} / \mathrm{m}$ conversion (5 not included as this conversion level cannot be reached with this catalyst).

studying the differences in activity. In addition, there is a significant variation in total pore volume $(\sim 20 \%)$, while the micropore volume remains largely unchanged $(<2 \%)$. The maximum total pore volume is found for catalyst 1 , which is in line with the other textural parameters. On the other hand, catalyst 4 is characterised by the smallest total pore volume, while its external area is above average. Fig. 6 shows that a type IV adsorption-desorption isotherm is obtained for catalyst 4, instead of the type I expected for microporous materials [30] and indeed seen for the others (only catalyst 2 is shown as example). Catalyst 4 must therefore include also a small amount of mesopores; their volume is too small, however, compared to the intercrystalline space to impact the total mesopore volume. The beneficial role that mesopores might play has already been highlighted for the H-Beta-catalysed OA alkyl isomerisation, where high conversion was linked to a large amount of mesopores [31].

\subsubsection{Acidity type and accessibility}

Catalyst 5, with a much higher $\mathrm{Si} / \mathrm{Al}$ ratio, shows a very low activity but a high selectivity. However, the Si/Al ratios for the four remaining catalysts lie between 8.5 and 10, and this narrow range does not explain the large observed differences in activity and selectivity. Therefore, other acidity-determining parameters have been systematically investigated, in order to determine whether any link can be made with the observed performance of the catalysts.

FTIR spectroscopy has been used to probe the Brønsted acid sites responsible for the alkyl isomerisation, and any Lewis acid sites if present. $d_{3}$-Acetonitrile is generally used as is able to probe all acidic sites of the two-dimensional 10- and 8-MR channel structure [5]. We chose to use pyridine as probe instead (Py, kinetic diameter of $0.6 \mathrm{~nm}$ ), in order to focus on the acid sites located in the 10-MR channels, and those accessible from these channels [5]. As a result of the pore-mouth catalysis, only (part of) these channels are believed to take part in the isomerisation of the long-chain OA molecules [20]. Fig. 7 gives the FTIR spectra between 1600 and $1400 \mathrm{~cm}^{-1}$ with the key ring vibrations of the adsorbed Py. All five commercial catalysts show mostly Brønsted acidity; from the 4 major bands assigned to the protonated Py [32], the band at $1543 \mathrm{~cm}^{-1}$ was used to determine the relative Brønsted acidity, later shown to correlate with the activity. The very small band at $1454 \mathrm{~cm}^{-1}$ confirms that the Lewis acidity of the samples is insignificant compared to the Brønsted acidity, even after correction of the peak intensities for their extinction coefficients (respec-

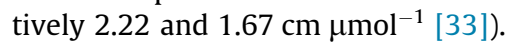

\subsubsection{External crystallite acidity}

Two methods have been used to study the external crystallite acidity. Firstly, a combination of XPS and argon ion sputtering enabled us to check for any acidity gradients in the outer layer of the crystallites. Fig. 8 shows the resulting $\mathrm{Si} / \mathrm{Al}$ ratios obtained for the commercial H-Fer series directly, and after $30 \mathrm{~s} / 300 \mathrm{~s}$ sputtering. Unsurprisingly, sample 5 shows the highest Si/Al ratio, although it is somewhat lower than the manufacturer-specified number; it is also the only catalyst with a higher $\mathrm{Si} / \mathrm{Al}$ ratio after sputtering. On the other hand, the Si/Al of the outer layer as measured by XPS $(1<2 \sim 4<3)$ does not exactly follow the manufacturer-specified $\mathrm{Si} / \mathrm{Al}(1 \sim 2<3 \sim 4)$; the Si/Al ratio above 10 measured for catalyst 2 could be explained by some slight dealumination during the wet activation.

The $\mathrm{Si} / \mathrm{Al}$ ratio of the outer layer for catalysts 2 and 4, as measured by XPS, is similar. However, this gives no indication of the accessibility of the acid sites to the OA. To assess any differences in accessibility, we used a bulky Lewis base (TPP) as a probe and quantified TPP chemisorption by diffuse reflectance UV-Vis spectroscopy. This way, it was possible to quantify the non-selective external acid sites in catalysts 2 and 4 (Fig. 9). The use of TPP specifically is based on results from catalytic testing, in which it has been shown to enhance selectivity of H-Fer-catalysed alkyl isomerisation of $\mathrm{OA}$ by preventing unwanted oligomerisation reactions $[19,20]$. The spectra recorded for catalysts 2 and 4 after reaction with TPP show 3 distinctive bands: an intense one at $226 \mathrm{~nm}$ and two smaller ones at 267 and $274 \mathrm{~nm}$, all originating from TPP cations. Interestingly, the intensity of the bands at 226, 267 and $274 \mathrm{~nm}$ for catalyst 2 is about two times larger than that for catalyst 4 , clearly showing that there are about twice as many non-selective sites on the external surface of sample 2 .

These results, together with the equivalence of the outer acidity profile of the two catalysts measured by XPS, show that a number of acid sites close to the external surface are not accessible to TPP for catalyst 4 , for example, they must be located in the pore mouth of smaller channels or in small pockets close to the external surface.

\subsubsection{Effective and intrinsic acid strength}

The number and effective strength of all acid sites in the commercial H-Fer samples were first determined by ammonia TPD. The manufacture-specified $\mathrm{Si} / \mathrm{Al}$ ratio is, as expected, well 


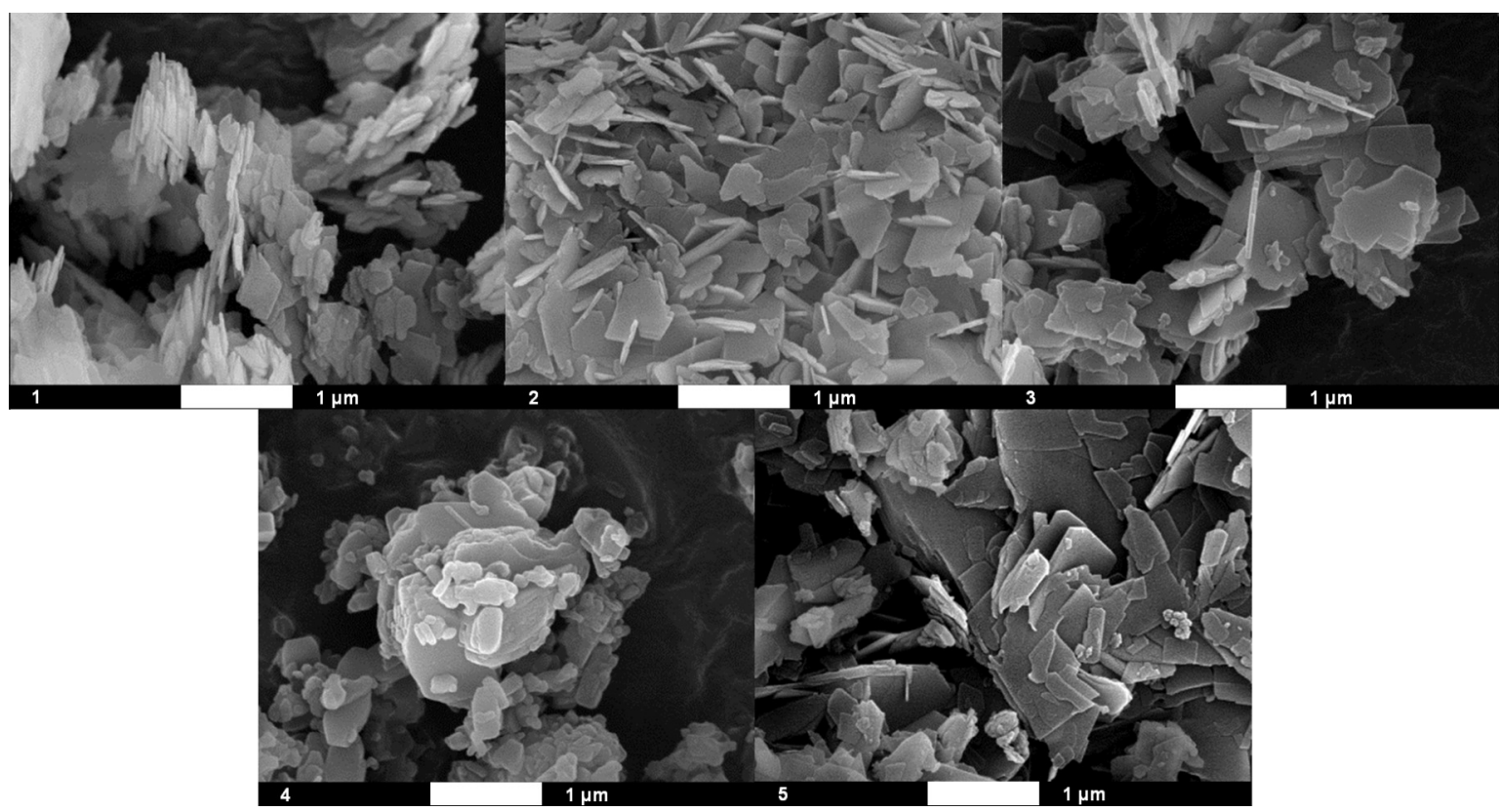

Fig. 5. Scanning electron microscopy images of the commercial H-Fer catalysts 1 to 5 .

Table 3

Particle size distributions of the commercial H-Fer catalysts; All particles (i.e., crystal agglomerates) are ranked based on their size and the diameter is reported for $10 \%$, $50 \%$ (median) and $90 \%$ of the particle count.

\begin{tabular}{llll}
\hline Catalyst \# & Diameter $(\mu \mathrm{m})$ 10\% & Diameter $(\mu \mathrm{m}) 50 \%$ & Diameter $(\mu \mathrm{m}) 90 \%$ \\
\hline 1 & 1.3 & 4 & 9 \\
2 & 3.4 & 14 & 36 \\
3 & 1.3 & 5 & 15 \\
4 & 0.9 & 3 & 7 \\
5 & $\mathrm{ND}^{\mathrm{a}}$ & $\mathrm{ND}^{\mathrm{a}}$ & $\mathrm{ND}^{\mathrm{a}}$ \\
\hline
\end{tabular}

a Not determined.

correlated with the total acidity found with this technique (Table 5). All curves (Fig. 10) show two peaks, one around $200^{\circ} \mathrm{C}$ and one between 400 and $500{ }^{\circ} \mathrm{C}$. The latter corresponds to the stronger acid sites that must be involved in alkyl isomerisation. Note that the temperature maxima for both peaks shift towards lower temperature down the series from 1 to 5 (Table 5). There is a weak negative correlation between the bulk $\mathrm{Si} / \mathrm{Al}$ ratio (as indicated by the manufacturer) and the temperature maxima for the peak at $400-500{ }^{\circ} \mathrm{C}$; this trend, which is based on the limited data set and variation observed within it, does not seem to be influenced by the platelet morphology. Indeed, the longest desorption time (as measured to the maximum of the second TPD peak) corresponds to catalyst 1 that comprises the smallest crystals, while the shortest desorption time is measured for catalyst 5 comprising the largest ones. For all catalysts, the 10-MR channels are running along the crystal length, so if there was redeposition or diffusion

Table 4

Overview of textural properties of commercial $\mathrm{H}$-Fer catalysts based on $\mathrm{N}_{2}$ physisorption.

\begin{tabular}{llll}
\hline $\begin{array}{l}\text { Catalyst } \\
\#\end{array}$ & $\begin{array}{l}S_{\mathrm{E}}, \text { external area } \\
\left(\mathrm{m}^{2} / \mathrm{g}\right)\end{array}$ & $\begin{array}{l}V_{\mathrm{T}}, \text { total pore volume } \\
\left(\mathrm{cm}^{3} / \mathrm{g}\right)\end{array}$ & $\begin{array}{l}V_{\mu}, \text { micropore volume } \\
\left(\mathrm{cm}^{3} / \mathrm{g}\right)\end{array}$ \\
\hline 1 & 52 & 0.235 & 0.126 \\
2 & 32 & 0.212 & 0.124 \\
3 & 36 & 0.206 & 0.124 \\
4 & 40 & 0.193 & 0.124 \\
5 & 32 & 0.229 & 0.126 \\
\hline
\end{tabular}
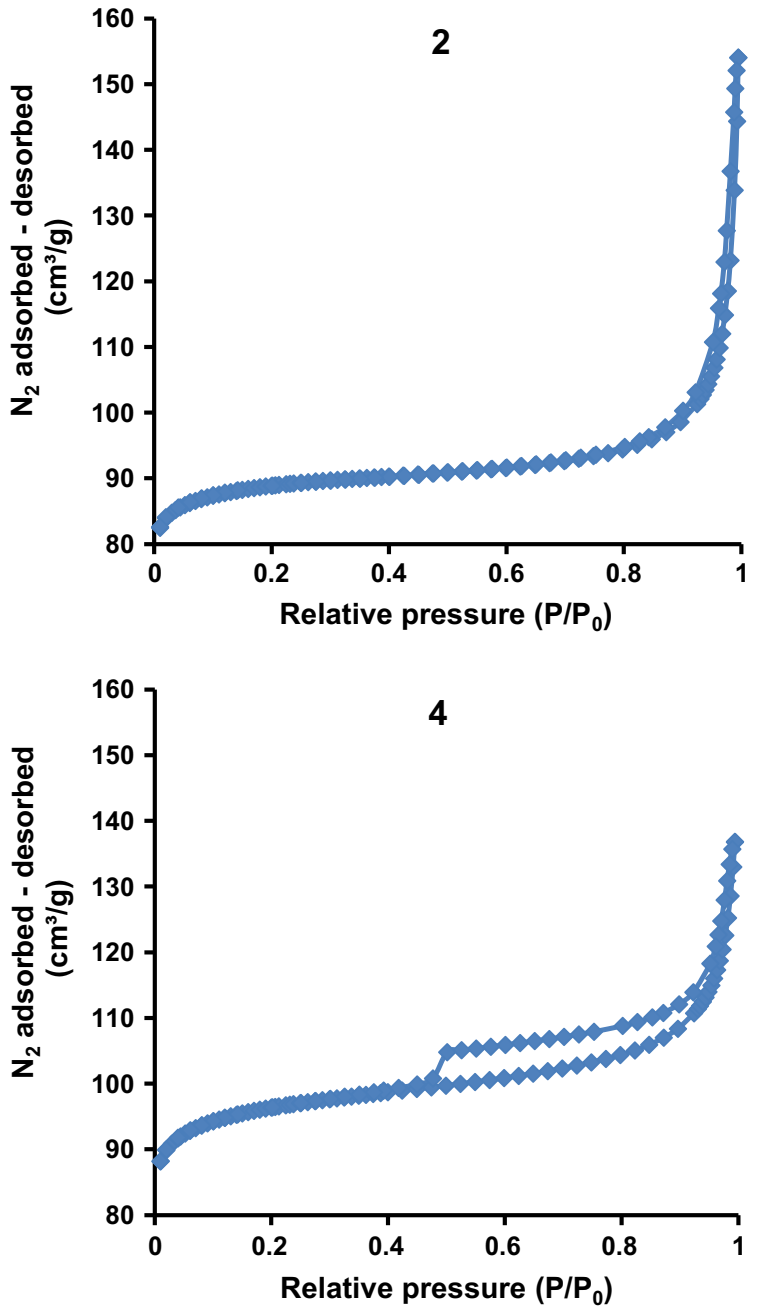

Fig. 6. Comparison of nitrogen adsorption-desorption isotherms of two commercial H-Fer catalysts: 2 (top) and 4 (bottom). 


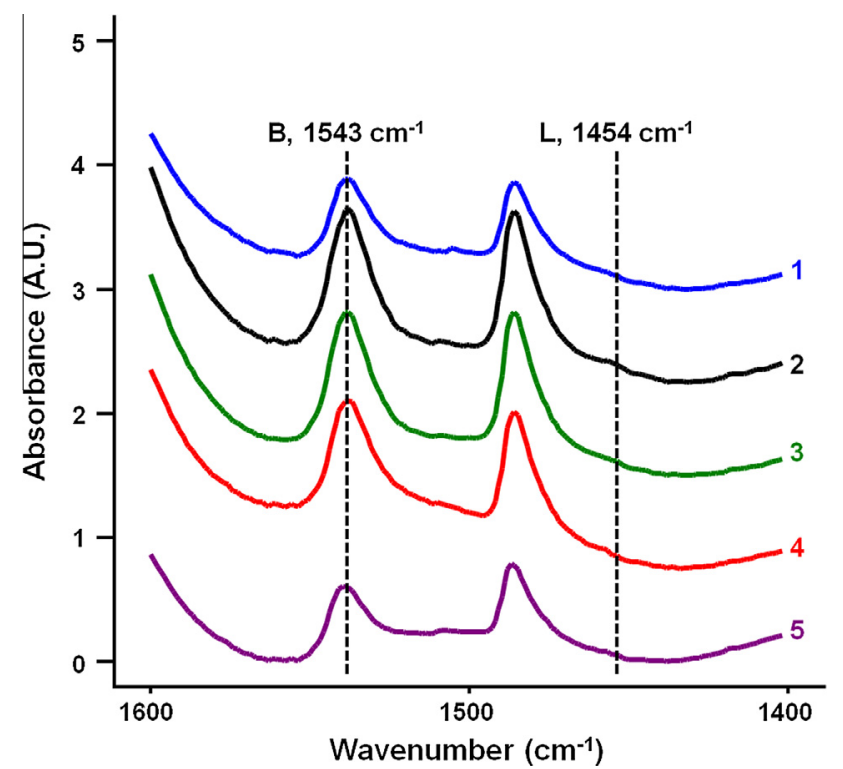

Fig. 7. IR absorbance spectra of the commercial H-Fer catalysts 1-5, after adsorption of Py at $50^{\circ} \mathrm{C}$ and desorption at $150{ }^{\circ} \mathrm{C}$.

limitations of $\mathrm{NH}_{3}$ in the $10-\mathrm{MR}$ channels, the opposite result would be expected.

In addition, the intrinsic strength of the Brønsted acid sites has been probed by FTIR analysis after $\mathrm{CO}$ adsorption/desorption. The spectra (in both the hydroxyl stretching and CO stretching regions) collected for all samples during the experiments are given in the supporting information (Figs. S2-S6). The CO-induced shifts are given in Table 5. Based on this technique, the acidity of the "exposed" acid sites (10-MR channels and cavities of the 8-MR channels [35]) is rather similar for all catalysts. The data point at very slightly lower proton affinities for samples 4 and 5; this is consistent with the evidence that catalyst 4 is dealuminated and the fact that catalyst 5 has a higher Si/Al ratio. The values found for samples 2 and 4 are also slightly higher than those of the literature (see Table 1 in the introduction), but show a similar trend. Analysis of the $\mathrm{CO}$ stretching region revealed the presence of a

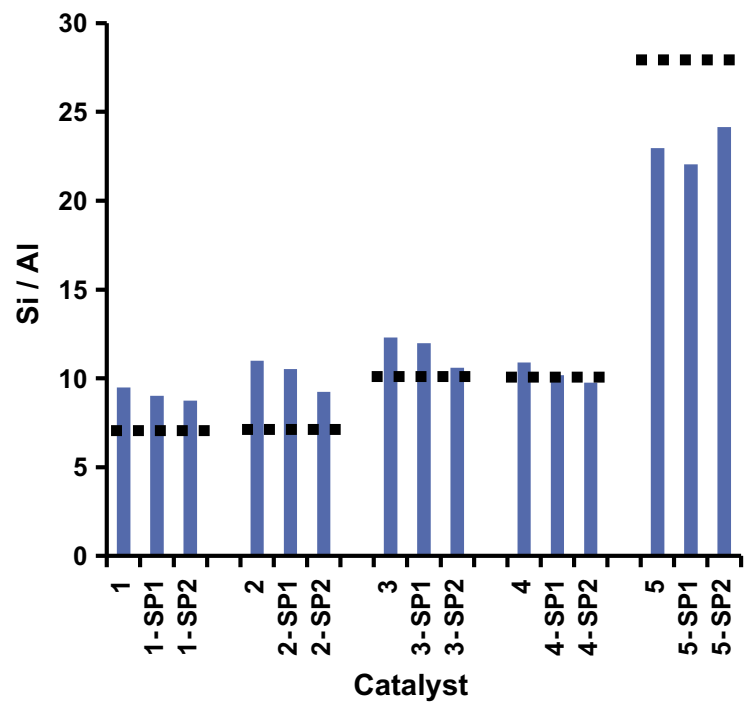

Fig. 8. Si/Al of the commercial H-Fer catalysts $1-5$, determined by XPS of the original samples and after Ar sputtering (SP1 after $30 \mathrm{~s}$ and SP2 after $300 \mathrm{~s}$ ); the nominal $\mathrm{Si} / \mathrm{Al}$ is given as a horizontal dashed line for each catalyst.

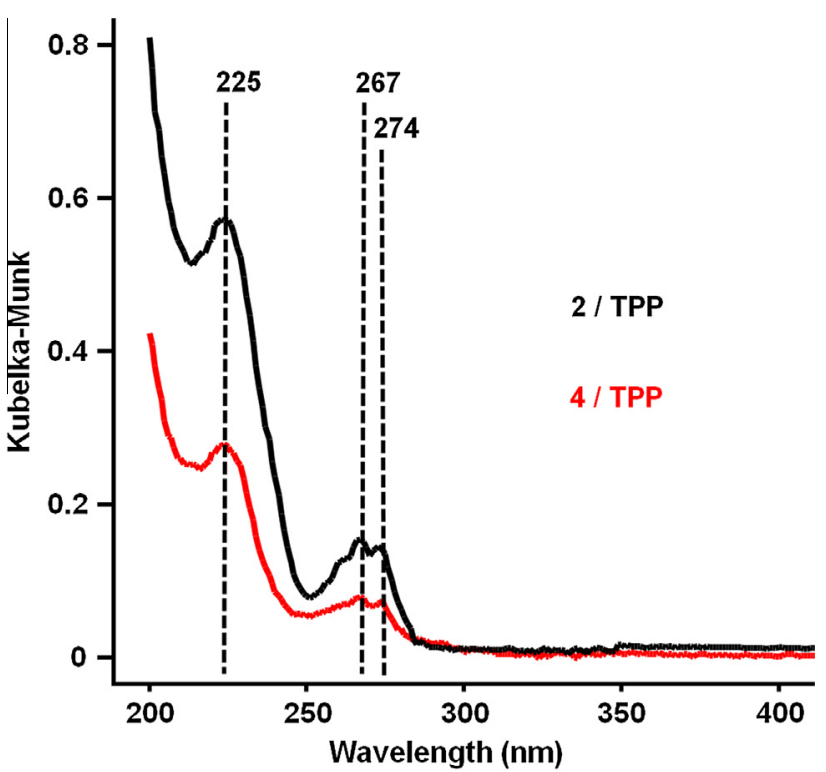

Fig. 9. Overlay of diffuse reflectance UV-Vis spectra of two commercial H-Fer catalysts 2 and 4, after reaction of their external acid sites with TPP; the spectra have been individually recorded and treated.

small amount of $\mathrm{K}^{+}$ions in the 10-MR channels and 8-MR channels of sample 2 (Fig. S3b), a small amount of $\mathrm{K}^{+}$ions in the 8-MR channels of sample 3 (Fig. S4b), a residual amount of coordinatively unsaturated $\mathrm{Al}^{3+}$ ions in sample 1 (Fig. S2b) and some EFAl in samples 1, 4 and 5 (Figs. S2b, S5b and S6b respectively) [35-36].

Finally, deconvolution of the hydroxyl range at $-188^{\circ} \mathrm{C}$ before introduction of CO (Fig. S1) gave the peak areas of the Brønsted acid sites in (i) the 10-MR channels, (ii) the large pockets of the 8-MR channels, (iii) the 8-MR channels, iv) the 6-MR, as well as the EFAl (see Table S1 in the supporting information). The distribution of these sites varies significantly between the 5 catalysts. Assuming that their extinction coefficients are similar, the 10-MR channels account for $12 \%$ of $\mathrm{Si}(\mathrm{OH}) \mathrm{Al}$ for catalysts 4 and $5,15 \%$ for catalysts 1 and 2 and $22 \%$ for catalyst 3 .

\section{Discussion}

Taken together, the data obtained with various analytical techniques for the five commercial ferrierite catalysts provide further insight into the relationship between their structure, and their activity and selectivity in the liquid-phase isomerisation of linear unsaturated fatty acids. Despite four of the five having very similar $\mathrm{Si} / \mathrm{Al}$ ratios, they show significant differences in OA conversion, as well as in (Mo)BUFA yields. With regard to their bulk properties, the $\mathrm{Si} / \mathrm{Al}$ ratios are consistent with the acid site quantification based on ammonia TPD (Table 5): $1-2>3>4 \gg 5$. The acid site concentration found by TPD is also reasonably in line with the literature data on total $\mathrm{Al}$ content $(1.65 \mathrm{mmol} / \mathrm{g}$ for catalyst 2 [34]; $1.56 \mathrm{mmol} / \mathrm{g}$ for catalyst 4 [16] and $0.55 \mathrm{mmol} / \mathrm{g}$ for catalyst 5 [16]). Therefore, with the exception of catalyst 5, a difference in $\mathrm{Si} / \mathrm{Al}$ ratio of less than $20 \%$ has a significant effect for this application. In addition, the TPD results, together with the absence of EFAl (as evidenced by the FTIR data after CO adsorption), confirm that catalyst 2 has not suffered any significant dealumination, despite the activation by ion exchange with $\mathrm{HCl}$. This method was selected instead of the milder $\mathrm{NH}_{4} \mathrm{NO}_{3}$ exchange as it proved to be convenient and reproducible.

Additionally, these catalysts are characterised by similar morphologies and textural properties; only their external surface areas 
Table 5

Overview of acidity parameters found for the commercial H-Fer by XPS, $\mathrm{NH}_{3}$-TPD and FTIR analysis after CO adsorption/desorption.

\begin{tabular}{|c|c|c|c|c|c|c|}
\hline $\begin{array}{l}\text { Catalyst } \\
\#\end{array}$ & $\begin{array}{l}\text { Nominal }^{\text {a }} \mathrm{Si} / \mathrm{Al} \\
\text { ratio }\end{array}$ & $\begin{array}{l}\text { Outer }{ }^{\mathrm{b}} \mathrm{Si} / \mathrm{Al} \\
\text { ratio }\end{array}$ & $\begin{array}{l}\text { TPD acid sites concentration } \\
(\mathrm{mmol} / \mathrm{g})\end{array}$ & $\begin{array}{l}\text { TPD 1st maximum } \\
\text { temperature }\left({ }^{\circ} \mathrm{C}\right)\end{array}$ & $\begin{array}{l}\text { TPD 2nd maximum } \\
\text { temperature }\left({ }^{\circ} \mathrm{C}\right)\end{array}$ & $\begin{array}{l}\text { Acid strength } \Delta v \mathrm{CO} \\
\left(\mathrm{cm}^{-1}\right)\end{array}$ \\
\hline 1 & 8.5 & 9.5 & 1.61 & 231 & 471 & 293 \\
\hline 2 & 8.5 & 11 & 1.66 & 213 & 461 & 292 \\
\hline 3 & 10 & 12 & 1.52 & 194 & 441 & 292 \\
\hline 4 & 10 & 11 & 1.35 & 195 & 414 & 298 \\
\hline 5 & 27 & 23 & 0.82 & 184 & 411 & 295 \\
\hline
\end{tabular}

\footnotetext{
a Commercial values.
}

b Measured by XPS.

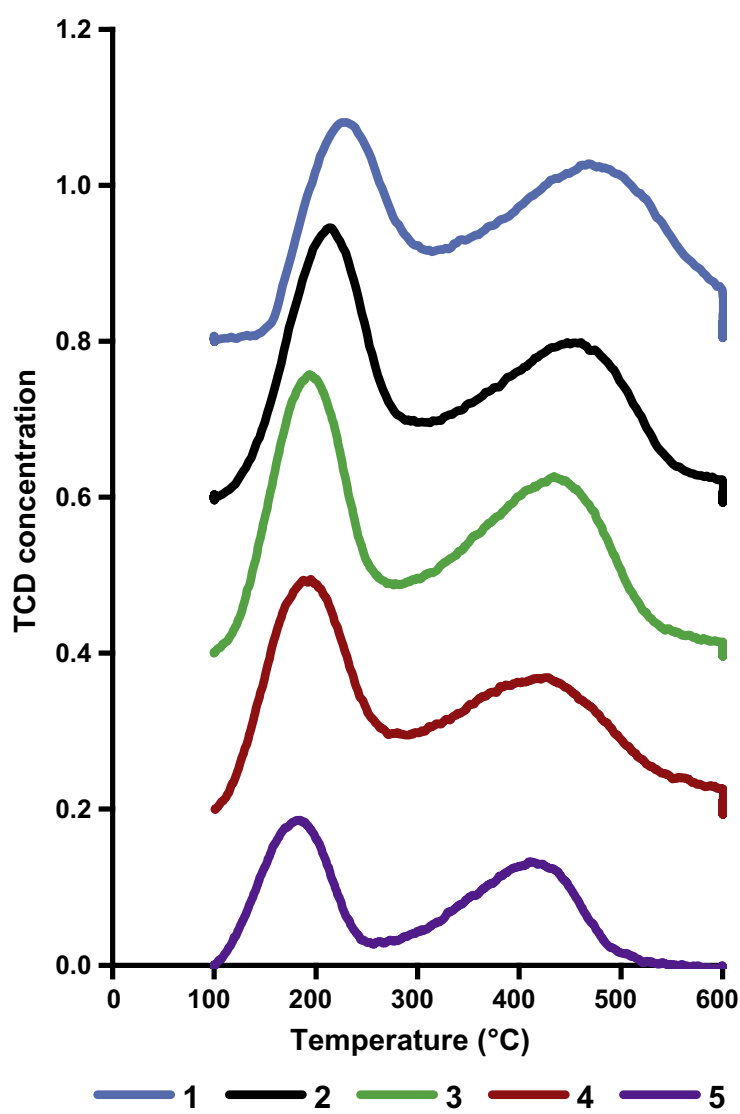

Fig. 10. Ammonia TPD profiles for the commercial H-Fer catalysts $1-5$; the $Y$ axis is proportional to the desorbed amount of $\mathrm{NH}_{3}$; traces are offset for clarity.

vary by $\sim 50 \%$. The latter is important though, and its variation can explain some of the differences observed in activity, as catalysis has been found to be constrained to the pore mouth due to very early pore blockage [20]. Due to previously observed gradual poisoning of the active sites, comparison of the catalyst activities must be done at an early stage of the reaction. The linearity of the conversion-time plots at low conversion (Fig. 1) is consistent with an active site model in which desorption of the branched species is the rate-limiting step (quasi-zero-order) [37]. At higher conversions, pore deactivation and competing reactions complicate the picture. Nonetheless, we observe that initial activity correlates well with the number of Brønsted acid sites present in the 10-MR channels, determined using Py as a 10-MR selective probe. This is illustrated in Fig. 11 (calculated at $t=8 \mathrm{~min}$ ). This relationship assumes that the distribution of Brønsted acid sites in the 10-MR channels is homogeneous, that is, the probability that an active site is found close to the pore mouth (and thus accessible for reaction) is proportional to the total number of active sites in the 10-MR channels,

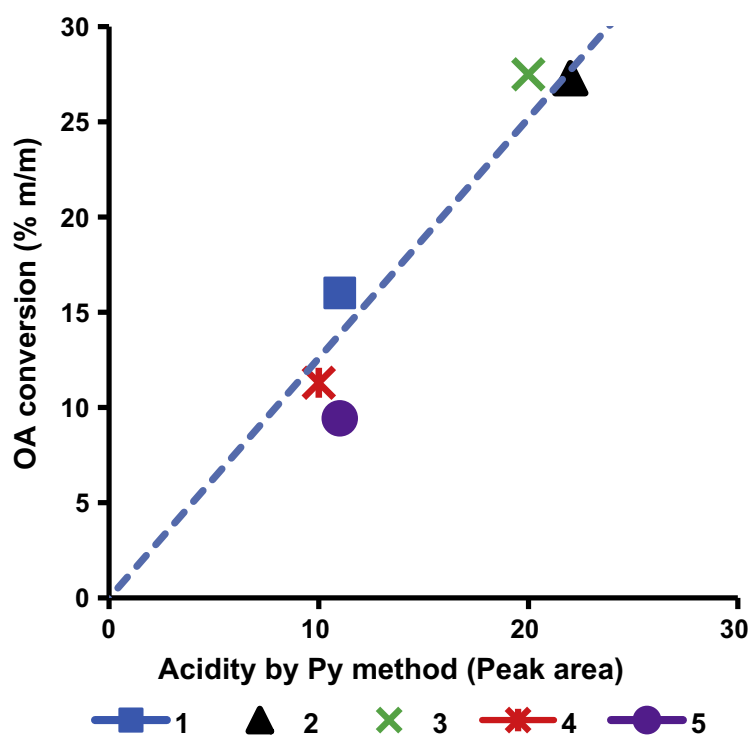

Fig. 11. Relation between Brønsted acid site concentration (Total integrated area for the peak at $\left.1543 \mathrm{~cm}^{-1}\right)$ as measured by Py-IR and the initial OA conversion $\left(y_{\mathrm{t}}\right)$ for the commercial $\mathrm{H}$-Fer catalysts at $t=8 \mathrm{~min}$.

as measured by Py desorption FTIR. By comparison, in the gas-phase isomerisation of butene to isobutene, a linear relationship was also found for isobutene yield (rather than butene conversion). In this case, the yield was found to be proportional to the total number of Brønsted acid sites, as determined by the acetonitrile probe (which in contrast to Py also probes Brønsted acid sites in the 8-MR channels) [34]; for the same reaction, the observed increase in selectivity with time-on-stream was also explained by pore-mouth catalysis. Additionally, smaller crystal size (for a given $\mathrm{Si} / \mathrm{Al}$ ratio) has been shown to increase isobutene selectivity for H-Fer catalysts, confirming the importance of the 10-MR pore-mouth density [8].

The relation seen between OA conversion and Brønsted acidity explains the differences between the five catalysts in terms of activity (i.e., they are the result of differences in overall Al distribution over the various possible T-sites), but it does not yet explain the differences observed in (Mo)BUFA selectivity. Indeed, the high Brønsted to Lewis acid site ratio of all catalysts (in line with findings from the literature [11]) explains the low level of oligomers and high BUFA yield found with all five catalysts, as reported in the alkyl isomerisation of butene to isobutene [10]. It cannot however explain the significant variation in selectivity within the monomeric fraction; this suggests that there must be other parameters at play.

A first indication of what determines these selectivity differences to/within the monomer fractions is given by the XPS studies. These measurements show that a lower acidity of the outer crystallite surface seems beneficial to monomer selectivity, although 
the correlation is not perfect; catalyst 4 is significantly more selective than 2, despite their equivalent outer XPS acidity profile. Based on the TPP results, we can further refine the requirements for selective BUFA formation. Indeed, our UV-Vis results after TPP chemisorption show that sample 2 is characterised by twice as many non-selective sites on its external surface. Some of the sites seen by XPS must therefore be barely accessible to the OA reactant. XPS is therefore unable to fully discriminate the accessibility of sites. UV-Vis with TPP is therefore a necessary supplementary technique to XPS, when catalysts with similar external acidity are compared, in order to predict differences in selectivity to BUFA.

This finding can be further substantiated by characterisation data reported earlier for these catalysts by Rachwalik et al. [17]; these authors compared the acidity of catalysts 2 and 4 by FTIR, and the resulting spectra were similar in the main features. However, the distribution of silanol groups is quite distinct; catalyst 4 has some silanol groups located inside zeolitic faults $\left(3730 \mathrm{~cm}^{-1}\right)$ and fewer external silanol groups $\left(3748 \mathrm{~cm}^{-1}\right)$. The authors concluded that this catalyst has been submitted to a post-synthesis treatment, which would have removed most of the external acidity. Our UV-Vis/TPP method shows an absence of non-selective sites for catalyst 4 , supporting their hypothesis; our SEM pictures, and the presence of mesopores (detected by physisorption), provide further evidence.

The highest selectivity to MoBUFA is found for catalysts 4 and 5 . CO probing with IR shows that they are characterised by the strongest Brønsted acid sites, but based on the deconvolution of the $\mathrm{OH}$-stretching range (see supporting information) their 10-MR channels contain the lowest concentration of these sites. On the other hand, catalyst 3 has somewhat weaker Brønsted acid sites, but approximately double the concentration in the 10-MR channels. We can conclude from these data that selectivity to MoBUFA is enhanced by having a low concentration of strong Brønsted acid sites in the 10-MR channels. Catalyst 1 cannot be compared in this way, as it appears to be incompletely crystallised (based on XRD and residual coordinatively unsaturated $\mathrm{Al}^{3+}$ ). For catalyst 2 , the traces of $\mathrm{K}^{+}$detected in the $10-\mathrm{MR}$ channels by $\mathrm{CO}$ probing mean that a number of $\mathrm{Si}(\mathrm{OH}) \mathrm{Al}$ in the 10 -MR channels are actually not activated. On the other hand, the Py study found the same number of Brønsted acid sites for catalysts 2 and 3 . Therefore, the presence of $\mathrm{K}^{+}$must limit the Py diffusion in the $10-\mathrm{MR}$ channels of catalyst 2 , and the density of $\mathrm{Si}(\mathrm{OH}) \mathrm{Al}$ in the extremities of these channels must be higher for this sample compared to sample 3 . The somewhat lower acidity combined with the higher density of the Brønsted acid sites is therefore consistent with the lower MoBUFA selectivity.

Notably, in the gas-phase alkyl isomerisation of butene to isobutene, catalyst 5 also showed a very high selectivity, which was explained by a non-interconnected nanoreactor model in which the low density of active sites in the channels decreases the chance of successive reactions [15]. Although our system has been shown to undergo early pore blockage, high selectivity to MoBUFA can be explained by a similar model where the nanoreactors are limited to the channel extremities, consistent with the pore-mouth hypothesis.

If we compare the $\mathrm{NH}_{3}$-TPD curves recorded for our catalyst series, the maxima recorded for the second peak (corresponding to those sites strong enough to induce alkyl isomerisation) shift towards lower temperature (Table 5), and a negative correlation between these maxima and MoBUFA selectivities is found. This apparent contradiction with the IR study of $\mathrm{CO}$ adsorption/desorption can be explained by the fact that $\mathrm{NH}_{3}$ is probing all acid sites. Since the Brønsted acid sites are heterogeneous [38] and their distribution in the various channels varies significantly between catalysts, TPD thus reflects better the relative amount of the strong acid sites in the 10-MR channels. Therefore, the selectivity of
H-Fer to MoBUFA depends not only on its specific channel dimensions and external/internal location of the acid sites, but also on its effective acidity.

\section{Conclusions}

The liquid-phase skeletal isomerisation of OA has been studied in the presence of different commercial H-Fer. Despite four of the five having very similar Si/Al ratios, they show significant differences in activity, and selectivity towards the monomeric, BUFA and MoBUFA fractions. A number of complementary characterisation techniques have been used to assess their acidity in detail, including type, location, accessibility and strength. The initial activity was found to be related to the Brønsted acidity in the 10-MR channels. A low density of external acid sites enhances the selectivity to monomeric acids, while a high ratio of Brønsted to Lewis sites promotes the BUFA yield. MoBUFA selectivity was found to require few Brønsted acid sites of high strength in the 10-MR channel, reflected in a decrease of the effective acidity as seen by $\mathrm{NH}_{3}$-TPD. Together, the results presented on activity and catalyst structure show that catalyst 4 is the best commercial catalyst for this application, and also provide insight into why its low external acidity and low density of strong Brønsted acidity in the 10-MR channels are beneficial for performance. Finally, the results presented provide detailed insights into the required characteristics in terms of acidity of an efficient OA isomerisation catalyst. The relationships found between structure and activity may serve as guidelines for the synthesis of even more efficient catalysts.

\section{Acknowledgments}

The authors thank Croda for providing financial support. Tiny Verhoeven (Eindhoven University of Technology) is gratefully acknowledged for carrying out the XPS analyses. We would also like to thank Marjan Versluijs-Helder (Utrecht University) for performing the XRD and SEM analyses, and Arjan den Otter and dr. Jinbao Gao (Utrecht University) for helping with the physisorption measurements. Fouad Soulimani and dr. Hendrik van der Bij, both from Utrecht University, are thanked for support and advice in IR matters. Pascal Wijten (Utrecht University) is acknowledged for his assistance with the multi-autoclave operation. Finally, Negar Rashidi and Marvin Burger, both from Croda, contributed by carrying out a number of syntheses and analyses.

\section{Appendix A. Supplementary material}

Supplementary data associated with this article can be found, in the online version, at http://dx.doi.org/10.1016/j.jcat.2015.05.013.

\section{References}

[1] P. Granvallet, K.P. de Jong, A.G.T.G. Kortbeek, B. Kraushaar-Czarnetzki, H.H. Mooiweer, European Patent 0501577A1, 1992 (to Shell).

[2] C.L. O'Young, R.J. Pellet, D.G. Casey, J.R. Ugolini, R.A. Sawaicki, J. Catal. 151 (1995) 758 .

[3] B. de Ménorval, P. Ayrault, N.S. Gnep, M. Guisnet, Appl. Catal. A: Gen. 304 (2006) 1.

[4] P.A. Vaughan, Acta Crystallogr. 21 (1966) 983.

[5] T.M. Davis, C.-Y. Chen, N. Žilková, D. Vitvaroná-Procházková, J. Čejka, S. Zones, J. Catal. 298 (2013) 84

[6] F.R. Ribeiro, F. Alvarez, C. Henriques, F. Lemos, J.M. Lopes, M.F. Ribeiro, J. Mol. Catal. A: Chem. 96 (1995) 245.

[7] S. van Donk, J.H. Bitter, K.P. de Jong, Appl. Catal. A: Gen. 212 (2001) 97.

[8] S.-H. Lee, C.-H. Shin, S.B. Hong, J. Catal. 223 (2004) 200.

[9] J. Houzvicka, V. Ponec, Appl. Catal. A: Gen. 145 (1996) 95.

[10] J. Houzvicka, J.G. Nienhuis, V. Ponec, Appl. Catal. A: Gen. 174 (1998) 207.

[11] G.D. Pirngruber, K. Seshan, J.A. Lercher, Micropor. Mesopor. Mater. 38 (2000) 221.

[12] V.L. Zholobenko, D.B. Lukyanov, J. Dwyer, J. Phys. Chem. B 102 (1998) 2715. 
[13] C. Márquez-Alvarez, A.B. Pinar, R. García, M. Grande-Casas, J. Pérez-Pariente, Top. Catal. 52 (2009) 1281.

[14] M. Trombetta, G. Busca, J. Catal. 187 (1999) 521.

15] B. de Ménorval, P. Ayrault, N.S. Gnep, M. Guisnet, Catal. Lett. 98 (2004) 211.

16] G. Onyestyák, Micropor. Mesopor. Mater. 104 (2007) 192.

[17] R. Rachwalik, M. Hunger, B. Sulikowski, Appl. Catal. A: Gen. 427-428 (2012) 98.

[18] H.L. Ngo, A. Nunez, W. Lin, T.A. Foglia, Eur. J. Lipid Sci. Technol. 108 (2007) 214

[19] H.L. Ngo, R.O. Dunn, E. Hoh, Eur. J. Lipid Sci. Technol. 114 (2012) 213.

[20] S.C.C. Wiedemann, J.A. Stewart, F. Soulimani, T. van Bergen-Brenkman, S Langelaar, B. Wels, P.C.A. Bruijnincx, B.M. Weckhuysen, J. Catal. 316 (2014) 24.

21] Z.C. Zhang M. Dery, S. Zhang. D. Steichen, J. Surf. Deterg. 7 (2004) 211.

[22] Helen.L. Ngo, R.D. Ashby, A. Nunez, J. Am. Oil Chem. Soc. 89 (2012) 1885.

[23] J. Cason, W.R. Winans, J. Org. Chem. 15 (1949) 139.

[24] H. Wagner, R. Luther, T. Mang, Appl. Catal. A: Gen. 221 (2001) 429.

[25] D.V. Kinsman, J. Am. Oil Chem. Soc. 56 (1979) 823A.

[26] K.D. Haase, A.J. Heynen, N.L.M. Laane, Fat. Sci. Technol. 91 (1989) 350.

[27] H.L. Ngo, R.O. Dunn, B. Sharma, T.A. Foglia, Eur. J. Lipid Sci. Technol. 113 (2011)
[28] R. Rachwalik, Z. Olejniczak, B. Sulikowski, Catal. Today 101 (2005) 147.

[29] T.A. Isbell, R. Kleiman, B.A. Plattner, J. Am. Oil Chem. Soc. 71 (1994) 169.

[30] S. Storck, H. Bretinger, W.F. Maier, Appl. Catal. A: Gen. 174 (1998) 137.

[31] S. Zhang, Z.C. Zhang, Catal. Lett. 115 (3-4) (2007) 114.

[32] T. Barzetti, E. Selli, D. Moscotti, L. Forni, J. Chem. Soc., Faraday Trans. 92 (1996) 1401.

[33] C.A. Emeis, J. Catal. 141 (1993) 347.

[34] B. Wichterlova, N. Zilkova, E. Uvarova, J. Cejka, P. Sarv, C. Paganini, J.A. Lercher, Appl. Catal. A: Gen. 182 (1999) 297.

[35] S. Bordiga, G. Turnes Palomino, C. Pazè, A. Zecchina, Micropor. Mesopor. Mater. 34 (2000) 67.

[36] K.I. Hadjiivanov, G.N. Vayssilov, in: B.C. Gates, H. Knozinger (Eds.), Advances in Catalysis, vol. 47, Elsevier, USA, 2002, pp. 371-372.

[37] R.A. van Santen, P.W.N.M. van Leeuwen, J.A. Moulijn, B.A. Averill, in: B. Delmon, J.T. Yates (Eds.), Catalysis: An integrated Approach, vol. 123, Elsevier, Amsterdam, 2000, pp. 82-92 (Stud. Surf. Sci. Cat.).

[38] K. Chakarova, K. Hadjiivanov, Micropor. Mesopor. Mater. 177 (2013) 59. 